\title{
Y-box-binding protein 1 contributes to IL-7-mediated survival signaling in B-cell precursor acute lymphoblastic leukemia
}

\author{
AMINA KARIMINIA ${ }^{1 *}$, SABINE M. IVISON ${ }^{1 *}$, VIVIAN M. LEUNG ${ }^{1}$, SUSANNA SUNG $^{1}$, NICOLE COUTO $^{1}$, \\ JACOB ROZMUS $^{1}$, NINA ROLF ${ }^{1}$, ARU NARENDRAN ${ }^{2}$, SANDRAE. DUNN $^{1}$, \\ GREGOR S.D. REID ${ }^{1}$ and KIRK R. SCHULTZ ${ }^{1}$ \\ ${ }^{1}$ Michael Cuccione Childhood Cancer Research Program, Child and Family Research Institute, \\ Department of Pediatrics, University of British Columbia, Vancouver, BC V5Z 4H4; \\ ${ }^{2}$ Division of Pediatric Oncology, Alberta Children's Hospital, Calgary, AB T2N 4N1, Canada
}

Received May 2, 2016; Accepted September 27, 2016

DOI: $10.3892 / 01.2016 .5437$

\begin{abstract}
Y-box-binding protein 1 (YB-1) is a regulatory protein that is associated with drug resistance and relapse in solid tumors. As YB-1 mediates some of its activity through growth factor receptor signaling dysregulation, the present study compared the expression of YB-1 and interleukin 7 (IL-7) receptor $\alpha(\mathrm{IL}-7 \mathrm{R} \alpha)$ in pediatric B-cell precursor (BCP) acute lymphoblastic leukemia (ALL) and normal BCP cells. The expression levels of IL-7R $\alpha$ and YB-1 were higher in relapsed vs. diagnostic samples of primary BCP ALL; however, co-expression was also observed in a minor BCP cell population in samples from healthy donors. Functional crosstalk between YB-1 and IL-7R was detected: Overexpression of YB-1 increased surface levels of IL-7R in B cells, and the stimulation of BCP ALL cell lines and primary samples by IL-7 activated YB-1 by phosphorylation at S102 in a phosphatidylinositol 3-kinase-independent and MEK1/2-dependent manner. Targeted knockdown of YB-1 reduced IL-7-mediated protection against rapamycin, and an inhibitor of MEK1/2 potentiated rapamycin-mediated killing in the presence of IL-7. These data establish a novel link between two well-characterized pro-survival factors in acute leukemia, and suggest that YB-1 inhibition may represent a novel therapeutic strategy for increasing sensitivity to chemotherapy in patients with refractory acute B-cell leukemia.
\end{abstract}

Correspondence to: Dr Kirk R. Schultz, Present address: 4480 Oak Street, B315, Vancouver, BC V6H 3V4, Canada

E-mail:kschultz@mail.ubc.ca

${ }^{*}$ Contributed equally

Abbreviations: YB-1, Y-box-binding protein-1; BCP, B-cell precursor; ALL, acute lymphoblastic leukemia; IL-7R, interleukin-7 receptor

Key words: acute lymphoblastic leukemia, interleukin-7, Y-box-binding protein 1, relapse

\section{Introduction}

B-cell precursor acute lymphoblastic leukemia (BCP ALL) is the most common type of cancer that occurs during childhood. Although the majority of patients may be cured by the currently available therapeutic regimens, novel treatments are urgently required for the $20 \%$ of patients who experience relapse (1). The prevalence of BCP ALL may result, in part, from the fact that transformation generally occurs in cells arrested at the B-cell receptor checkpoint, a stage of differentiation associated with a balance between proliferation and recombination-activating gene-mediated DNA rearrangement (2-4). The stromal cytokine interleukin (IL)-7 serves an important role during this highly ordered process of differentiation, proliferation and somatic recombination (5-7). IL-7 binds to a receptor (IL-7R) that is composed of cluster of differentiation (CD) 127 (IL-7R $\alpha$ ) and CD132 $(\gamma \mathrm{c})$, which is found on lymphoid progenitor cells, BCP cells and $\mathrm{T}$ cells. It has been demonstrated that IL-7 facilitates the proliferation and survival of leukemia cells (8-10), contributes to the progression and relapse of leukemia $(11,12)$ and induces resistance to chemotoxins (13), thus contributing to the pathogenesis of ALL. As a result, identifying the leukemia-specific mediators of these IL-7-driven effects may enable the therapeutic targeting of this pathway.

Y-box-binding protein 1 (YB-1) regulates differentiation, proliferation and survival in a broad range of cells (14). In the cytoplasm, this highly conserved protein acts as a translational inhibitor to repress mRNA involved in survival and proliferation (15), whereas activation by stress and other factors leads to YB-1 phosphorylation and translocation to the nucleus where it functions as a transcription factor (16-18). Aberrant YB-1 expression may contribute to the development and maintenance of malignancy in several ways, including dysregulation of hormone/growth factor receptors (19-21), enhancement of survival during stress, and induction of drug resistance (22-25). Increased expression of YB-1 has been implicated as a poor prognostic factor in various different types of malignancy, including B-cell lymphoma (26-28). However, YB-1 expression has not yet been investigated in ALL. 
YB-1 functions downstream of growth factor receptors in other malignancies (29); therefore, it was hypothesized that YB-1 is involved in IL-7-mediated survival pathways in ALL. The present report describes a comparative analysis of YB-1 and IL-7R $\alpha$ expression in pediatric BCP ALL and normal precursor B cells, in order to determine whether crosstalk occurs between these two key regulators of proliferation and survival and whether YB-1 is involved in the IL-7-mediated protection of BCP ALL cells against rapamycin. The present study aimed to determine whether the inhibition of YB-1 may represent a novel strategy to increase the susceptibility of BCP ALL to mammalian target of rapamycin (mTOR) inhibitors.

\section{Materials and methods}

Cells, tissue samples and antibodies. Cell lines derived from relapsed human BCP ALL were obtained from commercial vendors: 697, 380, RCH-ACV and MHH-CALL-2 were purchased from DSMZ (Braunschweig, Germany); RS4;11 was acquired from ATCC (Manassas, VA, USA). All cell lines were cultured at $37^{\circ} \mathrm{C}$ in $5 \% \mathrm{CO}_{2}$ in RPMI 1640 medium supplemented with $10 \%$ heat-inactivated fetal bovine solution (FBS), $100 \mathrm{U} / \mathrm{ml}$ penicillin/streptomycin, and $2 \mathrm{mM}$ glutamine (all from Thermo Fisher Scientific Inc., Waltham, MA, USA), with the exception of MHH-CALL-2, which was cultured in RPMI with 20\% FBS. The phosphatidylinositol 3-kinase (PI3K) inhibitor LY294002 $(30 \mu \mathrm{M})$ and the Janus kinase (JAK) 1/2 inhibitor ruxolitinib (100 nM) were purchased from Selleck Chemicals (Houston, TX, USA), and the MEK1/2 inhibitor U0126 $(10 \mu \mathrm{M})$ was acquired from Cell Signaling Technology, Inc. (Danvers, MA, USA). The inhibitors in dimethyl sulfoxide (DMSO) were added $2 \mathrm{~h}$ prior to IL-7 stimulation. Cells were then incubated for a further $30 \mathrm{~min}$ after the addition of recombinant $25 \mathrm{ng} / \mathrm{ml}$ IL-7 (BioLegend, Inc., San Diego, CA, USA).

The use of human tissue samples was approved by the ethics boards of the British Columbia Children's and Women's Hospital (Vancouver, BC, Canada) and the Alberta Children's Hospital (Calgary, AB, Canada), in accordance with the Declaration of Helsinki. BCP ALL samples, obtained from surplus clinical tissue banked between November 1998 and July 2002, were of varied or unknown risk group classifications; the median ages of the patients at diagnosis $(n=20)$ and relapse $(n=7)$ were 6 years (range, $1-16$ years) and 13 years (range, 1-17 years), respectively. One adult BCP ALL relapse sample was included in the current study. Normal precursor and mature B cells were purchased as bone marrow mononuclear cells from Lonza Inc. (Allendale, NJ, USA) or obtained from fresh cord blood or bone marrow samples from pediatric non-hematological malignancy patients without bone marrow involvement. Xenograft-mediated expansion of primary $\mathrm{BCP}$

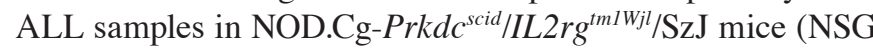
mice $^{\mathrm{TM}}$; Jackson Laboratory, Bar Harbor, ME, USA) was performed as previously described (30). All animal experiments were performed in accordance with a University of British Columbia Animal Care Committee-approved protocol (A11-0130).

Western blotting. Cell lines were harvested and lysed for $20 \mathrm{~min}$ on ice in the presence of a protease and phosphatase inhibitor cocktail (Roche Life Science, Benzberg, Germany) using 1X Cell lysis buffer from Cell Signaling Technology, Inc. (catalog no. 9803). After spinning down (18,000 x $g$ for $10 \mathrm{~min}$ at $4^{\circ} \mathrm{C}$ ), the amount of protein in the supernatant (lysate) was determined using the Pierce BCA Protein Assay kit (Thermo Fisher Scientific, Inc.), and an equal amount of protein was collected and mixed with Laemmli sample buffer and denatured for $5 \mathrm{~min}$ at $95^{\circ} \mathrm{C}$ followed by $1 \mathrm{~min}$ on ice. Proteins were separated on a $10 \%$ sodium dodecyl sulfate gel followed by electro-transfer blotting onto polyvinylidene difluoride membranes (BioRad, Hercules, CA, USA) using the Mini Trans-Blot Electrophoretic Transfer Cell device (BioRad). The membranes were then blocked using protease-free bovine serum albumin (catalog no. A7030; Sigma-Aldrich) blocking buffer ( $5 \% \mathrm{w} / \mathrm{v}$ in Tris-buffered saline). The following primary antibodies were used: PhosphoAKT ${ }^{\mathrm{S} 473}$ (catalog no. 5012), phospho-signal transducer and activator of transcription (STAT) $5^{\text {Y694 }}$ (catalog no. 9351), phosphoYB-1 ${ }^{\mathrm{S} 102}$ (catalog no. 2900), phospho42/44 MAPK [extracellular signal-regulated kinase (ERK) 1/2] ${ }^{\mathrm{T} 202 / \mathrm{Y} 204}$ (catalog no. 4370), total p90 ribosomal S6 kinase (RSK) 1 (catalog no. 8408), total AKT (catalog no. 4691), total STAT5 (catalog no. 9363) and total p42/44 (catalog no. 4695). Anti-total YB-1 was purchased from Abcam (Cambridge, UK; catalog no. ab12148) and anti-pRSK1/2 $221 / 227 / 218 / 232$ was obtained from Invitrogen (catalog no. PA5-37829; Thermo Fisher Scientific, Inc.). Anti-rabbit or -mouse immunoglobulin (Ig)G-horseradish peroxidase (HRP) was used as a secondary antibody (Biorad catalog no. 1721019). All antibodies were purchased from Cell Signaling Technology, Inc., unless otherwise stated and were used at a dilution of 1:1,000. Signals were detected using the Novex ECL HRP Chemiluminiscent Substrate Reagent kit, and captured on X-ray film (both from Invitrogen; Thermo Fisher Scientific, Inc.).

Flow cytometry. For detection of total YB-1 in hematogones and BCL ALL primary cells, frozen cells were thawed, washed and counted. A total of $1-2 \times 10^{6}$ peripheral blood mononuclear cells were stained with a 1:25 dilution of the following antibodies: CD19-peridinin chlorophyll (PerCP), CD10-allophycocyanin (APC), CD20-Brilliant ${ }^{\mathrm{TM}}$ Violet 421, CD45-APC-Cy7 and CD127-phycoerythrin (PE) antibodies (BioLegend, Inc.), and incubated for $15 \mathrm{~min}$ on ice. The cells were then fixed using BD Biosciences Fix buffer (BD Biosciences, Franklin Lakes, NJ, USA) for 15 min on ice and then permeabilized using Perm II buffer (BD Biosciences) for $10 \mathrm{~min}$ at room temperature. All cell washes were in $2 \% \mathrm{FBS}$ in phosphate buffered-saline (PBS) and the spun at $4^{\circ} \mathrm{C}$ and $500 \times \mathrm{g}$ for $5 \mathrm{~min}$. For detection of total intracellular YB-1, the cells were stained with a rabbit monoclonal antibody against YB-1 (Abcam; catalog no. ab76540) followed by anti-rabbit IgG-fluorescein isothiocyanate (BioLegend, Inc.; catalog no. 406403). Hematogones were identified as CD45 ${ }^{\mathrm{dim}}$, $\mathrm{CD} 19^{+}, \mathrm{CD} 20^{\text {dim to negative }}$ and $\mathrm{CD} 10^{+}$cells. Flow cytometry data was acquired using the BD LSRII with FACSDiva software ${ }^{\mathrm{TM}}$ V8 (BD Biosciences) and analyzed using FlowJo v9.2 (Tree Star, Inc., Ashland, OR, USA). Detection of phosphoYB-1 in primary cells or cell lines after IL-7 treatment was performed as aforementioned for total YB-1 but substituting the pYB-1 ${ }^{\mathrm{S} 102}$ antibody (catalog no. ab74162; Abcam). Primary transfected 
B-cells were stained at $24 \mathrm{~h}$ post-transfection for surface markers using CD19-PB (catalog no. 302223), CD127-PerCP (catalog no. 351322) (all 1/25 dilution; BioLegend, Inc.), then fixed/permeabilized and stained for intracellular YB-1 as aforementioned, with the exception that anti-rabbit IgG-PE (Biolegend, Inc.; catalog no. 406421) was used.

Knockdown and overexpression of YB-1. A total of $1 \times 10^{6}$ MHH-CALL-2 cells in PBS were transfected with $200 \mathrm{nM}$ small interfering RNA (siRNA), or 2-4 $\mu \mathrm{g}$ plasmid, using electroporation (Amaxa ${ }^{\mathrm{TM}}$ nucleofection, Lonza, Inc.) and the proprietary program C005. Silencer ${ }^{\circledR}$ Select stealth siRNA (Invitrogen; Thermo Fisher Scientific, Inc.), modified to extend cell half-life, was used for the targeted knockdown of YB-1. The universal negative control MEDGC (Invitrogen; Thermo Fisher Scientific, Inc.) served as a control for non-specific interactions. The siRNA sequences used for YB-1 knockdown were as follows: siRNA YB-1-1, 5'-CAAGGUAGACCAGUG AGGCAGAAUA-3'; siRNA YB-1-2, 5'-GGUCCUCCACGC AAUUACCAGCAAA-3'. Transcript and protein levels were determined by quantitative polymerase chain reaction (qPCR) or flow cytometry three days after transfection. RNA was extracted from the cells using the Qiagen RNAeasy Mini kit (Qiagen, Mississauga, ON, Canada) and cDNA synthesized with a first-strand cDNA synthesis kit (GE Healthcare Life Sciences, Chalfont, UK) using random primers. The TaqMan ${ }^{\circledR}$ Universal PCR Master Mix was used for qPCR with the TaqMan gene expression assay for human YB-1 (Hs00898625_g1), with human TATA-box binding protein (Hs99999910_m1) used as an endogenous control. Amplification was performed using a GeneAmp ${ }^{\circledR} 5700$ Sequence Detection system (40 cycles; $95.0^{\circ} \mathrm{C}$ for $15 \mathrm{sec}$ and $60.0^{\circ} \mathrm{C}$ for $\left.60 \mathrm{sec}\right)$. All qPCR reagents were purchased from Applied Biosystems (Thermo Fisher Scientific, Inc.). Quantification of RNA was performed using the $2^{-\Delta \Delta \mathrm{Cq}}$ method (31).

For overexpression of YB-1, CD19+ $\mathrm{B}$ cells were isolated from cord or peripheral blood using a RosetteSep ${ }^{\mathrm{TM}}$ Human B Cell Enrichment Cocktail (catalog no. 15064; Stemcell Technologies, Inc., Vancouver, BC, Canada) and $1 \times 10^{6}$ cells were transfected with the plasmid as described above; a pEGFP-based vector expressing the green fluorescent protein (GFP)/YB-1 fusion protein, which was generously provided by Dr Michel Lebel (Cancer Research Center of Laval University, QC, Canada), was used for overexpression (32), and pEGFP-C1 (Clontech Laboratories, Inc., Mountain View, CA, USA) served as a negative control.

Cytotoxicity assays. MHH-CALL-2 cells were incubated overnight with $25 \mathrm{ng} / \mathrm{ml}$ IL-7. IL-7 treatment was repeated $30 \mathrm{~min}$ prior to the addition of $140 \mu \mathrm{M}$ rapamycin (LC Laboratories, Woburn, MA, USA). After $8 \mathrm{~h}$, cells were harvested and the percentage of dead cells was determined by flow cytometry using the Fixable Viability Dye eFluor ${ }^{\circledR} 450$ (eBioscience Inc., San Diego, CA, USA).

For experiments combining rapamycin and U0126, cells were incubated for $2 \mathrm{~h}$ with $10 \mathrm{mM}$ U0126 or $0.15 \%$ DMSO and subsequently overnight with $25 \mathrm{ng} / \mathrm{ml} \mathrm{IL-7.} \mathrm{The} \mathrm{following}$ morning, cultures were administered a second dose of U0126 and IL-7 for $30 \mathrm{~min}$ prior to the addition of $34 \mu \mathrm{M}$ rapamycin for a further $18 \mathrm{~h}$. The percentage of dead cells was subsequently determined. The extent of apoptosis (A) induced by rapamycin with or without IL-7 and U0126 was calculated as previously described (28). The percent rescue with IL-7 was calculated as follows: Percent rescue $=\left[1-\left(\mathrm{A}^{\text {with IL-7 }} / \mathrm{A}^{\text {without IL-7 }}\right)\right] \times 100$.

Statistical analysis. To compare levels of YB-1 and IL-7 in different populations, selected data sets were analyzed by one-way analysis of variance with corrections for multiple comparisons. All other data sets were compared using an unpaired Student's t-test unless otherwise indicated. All tests were two-tailed. $\mathrm{P}<0.05$ was considered to indicate a statistically significant difference.

\section{Results}

Expression of IL-7R $\alpha$ and $Y B-1$ in normal and malignant $B C P$ cells. YB-1 is well established as a risk factor for various types of malignancy (14), and IL-7R $\alpha$ mediates proliferation and survival signaling in BCP ALL cells (33); therefore, the levels of these two proteins in normal BCP cells and unmatched BCP ALL cells obtained at diagnosis or relapse were compared. As shown in Fig. 1A, levels of YB-1 in BCP ALL at diagnosis and relapse were significantly higher than those of cells within the broader BCP cell population (defined as CD $45^{\mathrm{dim}} \mathrm{CD} 10^{+} \mathrm{CD} 19^{+}$) obtained from healthy donors $(\mathrm{P}=0.0018)$. Furthermore, levels of YB-1 expression were higher in relapsed BCP ALL than in diagnostic samples $(\mathrm{P}=0.0019)$. Similarly, IL-7R $\alpha$ expression levels were significantly higher in BCP ALL cells compared with normal $\mathrm{BCP}$ cells (Fig. $1 \mathrm{~B} ; \mathrm{P}=0.0286$ ); however, given the broad range of expression levels in the different patient samples, IL-7R $\alpha$ expression did not differ significantly between diagnostic and relapse samples. These data indicate that IL-7R $\alpha$ and YB-1 may serve a potential role in the onset and/or progression of BCP ALL. Therefore, it was investigated whether YB-1 and IL-7R co-expression was fully restricted to leukemic BCP cells.

As $90 \%$ of the primary ALL samples were $\mathrm{CD} 10^{+} / \mathrm{CD} 20^{\mathrm{dim}}$, the phenotypically equivalent normal BCP population was evaluated for YB-1 and IL-7R expression (Fig. 1C). This analysis demonstrated that a particular subset of cells, previously hidden in the more broadly defined $\mathrm{CD} 45^{\mathrm{dim}} \mathrm{CD} 10^{+} \mathrm{CD} 19^{+}$ BCP cell population, expressed YB-1 and IL-7R. In this cell subset, the mean fluorescence intensity for YB-1 staining of cells expressing IL-7R was not significantly different from that observed on diagnostic BCP ALL cells (data not shown). This result indicates that YB-1 is co-expressed with IL-7R in a small subset of normal B-cell progenitors, and therefore not restricted to leukemic cells.

Surface levels of $I L-7 R \alpha$ increase with overexpression of $Y B-1$. Having established that YB-1 and IL-7R $\alpha$ are highly expressed in BCP ALL and a subset of normal BCP cells, it was investigated whether the co-expression of the two proteins was functionally related. Previously, YB-1 has been demonstrated to regulate the expression of hormone and growth factor receptors in cancer $(19,20)$; therefore the effect of YB-1 overexpression on IL-7 receptor levels was evaluated. Peripheral blood- or cord blood-derived CD19+ $\mathrm{B}$ cells were transiently transfected with a YB-1-GFP fusion construct or a GFP control, and subsequently analyzed for IL-7R $\alpha$ surface 
expression. A comparison of GFP-positive cells in the two groups indicated that the marked increase in YB-1 expression in B cells containing the GFP/YB-1 plasmid was accompanied by an increase in the proportion of IL-7R $\alpha$-positive cells. IL-7R $\alpha$ expression did not change in the YB-1-negative fraction or in cells rendered GFP-positive by the control plasmid (Fig. 2A and B). While YB-1 expression alone was not always sufficient to increase the expression of IL-7R $\alpha$ (transfection of cells with YB-1-GFP increased the proportion of $\mathrm{YB}-1^{+} / \mathrm{IL}-7 \mathrm{R} \alpha^{-}$cells), this result supports the concept that surface expression of IL-7R $\alpha$ is influenced by YB-1 expression in B-lineage cells.

IL-7 induces phosphorylation of YB-1 in BCP ALL cell lines and patient samples. In the cytoplasmic compartment, YB-1 forms an inhibitory complex with mRNA. It has previously been demonstrated that phosphorylation at Ser102 activates YB-1, inducing the release and translation of mRNA and enabling nuclear localization for transcriptional regulation $(16,34,35)$. As pYB-1 ${ }^{\text {S102 }}$ is induced by epidermal growth factor stimulation in breast cancer cell lines (36), the ability of IL-7 to induce the phosphorylation of YB-1 in BCP ALL cells was examined. Several different BCP ALL cell lines (380, RS;4:11, 697, RCH-ACV and MHH-CALL-2) were stimulated with PBS or $25 \mathrm{ng} / \mathrm{ml} \mathrm{IL-7} \mathrm{for} \mathrm{5-60} \mathrm{min.} \mathrm{Western}$ blotting was subsequently performed to analyze the expression of phosphorylated and total YB-1 (Fig. 3A). Within 15 min of stimulation with IL-7, all of the cell lines exhibited YB-1 phosphorylation. Similar results were obtained for pYB-1 following intracellular flow cytometric analyses of the cell lines (data not shown). Furthermore, analysis of primary BCP ALL diagnostic samples (deidentified code nos. A193 and A199) and the primary BCP ALL relapse sample (deidentified code no. A247) by flow cytometry indicated an increase in pYB-1 ${ }^{\text {S102 }}$ within 5 min of IL-7 stimulation (Fig. 3B). Thus, IL-7 has the ability to activate YB-1 by S102 phosphorylation in BCP ALL cell lines and in primary samples of pediatric BCP ALL at diagnosis and relapse.

IL-7-mediated phosphorylation of YB-1 is MEK1-dependent and PI3K/Akt-independent. The binding of IL-7 to its receptor on BCP cells triggers a distinct set of responses including differentiation, proliferation and survival. JAK1/3 phosphorylates tyrosine residues on the IL-7R $\alpha$ chain allowing recruitment and activation of STAT1, 3 and 5 proteins (37), PI3K (38) and the Ras/Raf signaling cascade $(39,40)$. To identify which of these signaling pathways are involved in the IL-7-mediated phosphorylation of YB-1, the induction of these pathways in a BCP ALL cell line by IL-7 was assessed. Stimulation of CALL-2 cells with $25 \mathrm{ng} / \mathrm{ml} \mathrm{IL-7} \mathrm{induced} \mathrm{the}$ phosphorylation of STAT5 ${ }^{\mathrm{Y} 694}, \mathrm{Akt}^{\mathrm{S} 473}$ and ERK1/2 $202 / \mathrm{Y} 204$ (Fig. 4A). It has been demonstrated that RSK1/2, downstream of ERK1/2, is able to phosphorylate YB-1 (36); therefore, the induction of $\mathrm{pRSK}^{\mathrm{S} 221 / 5227}$ was investigated. RSK1 was strongly and constitutively phosphorylated; however, RSK2 was only transiently induced by IL-7 (Fig. 4A). To determine which signaling components were required for YB-1 phosphorylation, CALL-2 cells were treated with pharmacological inhibitors of the JAK/STAT, PI3K and Raf/ERK signaling pathways prior to IL-7 stimulation, and the phosphorylation of YB-1 was then examined (Fig. 4B). Inhibition of signaling downstream of PI3K with Ly294002 blocked phosphorylation of Akt completely; however, phosphorylation of YB-1 was only slightly reduced. Phosphorylation of YB-1 downstream of IL-7 was strongly inhibited by the MEK1/2 inhibitor U0126. Likewise, the JAK1/2 inhibitor ruxolitinib blocked all IL-7-induced signaling and thus phosphorylation of YB-1. Consistent with this finding, U0126 blocked the increase in levels of phosphorylated YB-1 in IL-7-stimulated ALL patient samples (Fig. 4C). These results indicate that IL-7-mediated activation of YB-1, in cell lines and patient-derived BCP ALL, requires MEK1/2.

YB-1 contributes to IL-7-mediated inhibition of rapamycin-induced cell death. Having identified YB-1 as an IL-7 signaling intermediate in BCP ALL, the functional significance of this relationship was examined. YB-1 is a prognostic marker for multi-drug resistance in many different types of cancer (22-25); thus, the finding that YB-1 expression is highest in relapsed BCP ALL suggests that YB-1 serves a potential role in contributing to chemotherapy resistance. The ability of IL-7 to protect BCP ALL cells against cell death has previously been demonstrated with the mTOR inhibitor rapamycin (13). In the present study, the role of YB-1 in this type of protection was assessed using two approaches: Targeted knockdown of YB-1 and pharmacological inhibition of YB-1 phosphorylation. Determination of YB-1 levels in CALL-2 cells $72 \mathrm{~h}$ following transfection with siRNA YB-1-1 or YB-1-2 demonstrated respective reductions of 88 and $68 \%$ in mRNA, and 67 and $37 \%$ in protein levels compared with control cells transfected with a non-specific control siRNA (Fig. 5A). Knockdown of YB-1 alone did not cause a significant decrease in cell viability in the absence or presence of IL-7 in the $24 \mathrm{~h}$ assay (Fig. 5B). To evaluate the effect of YB-1 knockdown on rapamycin sensitivity, $48 \mathrm{~h}$ after siRNA transfection, cells were treated overnight with IL-7 or vehicle control and then challenged with rapamycin for a further $8 \mathrm{~h}$. Even in the absence of IL-7, cells transfected with siRNA exhibited increased susceptibility to rapamycin ( 91 and $86 \%$ cell death for siRNA YB-1-1 and YB-1-2, respectively), compared with cells transfected with control siRNA (71\% cell death; Fig. 5B; $\mathrm{P}<0.05)$. In cells transfected with control siRNA, treatment with IL-7 reduced the proportion of dead cells following rapamycin challenge from 71 to $36 \%$, corresponding to $49 \%$ cell rescue. In cells transfected with siRNA targeting YB-1, IL-7 reduced the percentage of cell death following rapamycin treatment to 66\% (for siRNA YB-1-1) and 58\% (for siRNA YB-1-2); this corresponded to rescue rates of 27 and 33\%, respectively, which were significantly lower than the rescue rate obtained by IL-7 treatment of control siRNA-transfected cells (Fig. 5B; $\mathrm{P}<0.005$ and $\mathrm{P}<0.01$, respectively). This result indicates that YB-1 knockdown reduces the ability of IL-7 to protect BCP ALL cells against rapamycin.

To confirm the validity of the knockdown experiment results, the ability of MEK1/2 inhibition by U0126 (which was shown to completely inhibit IL-7-induced YB-1 phosphorylation) to augment cell death in response to rapamycin in cells with and without IL-7 pretreatment was evaluated. Rapamycin was added to U0126-treated cells which had been exposed to IL-7 or medium, and the percentage of dead cells was 
A

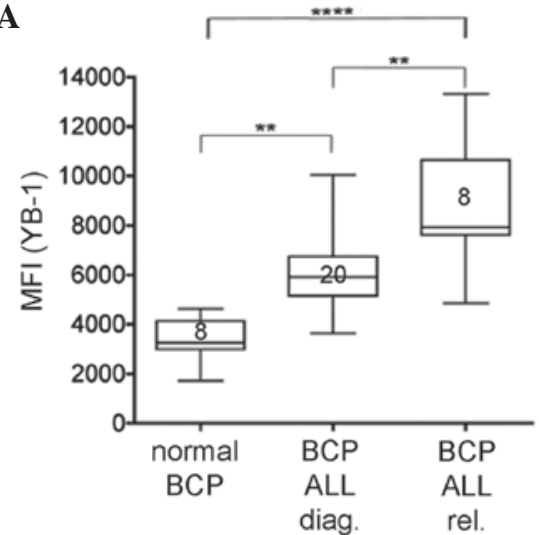

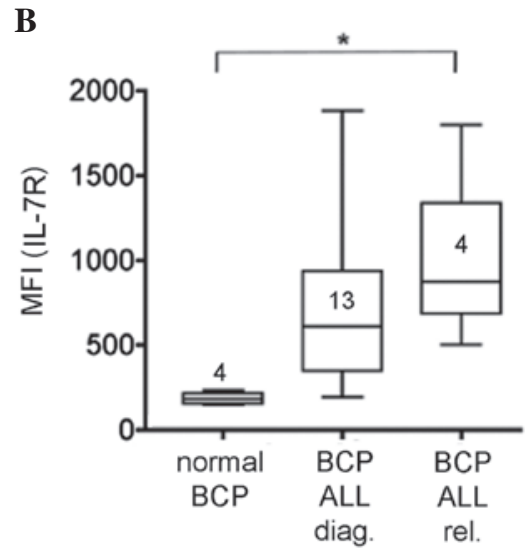

C

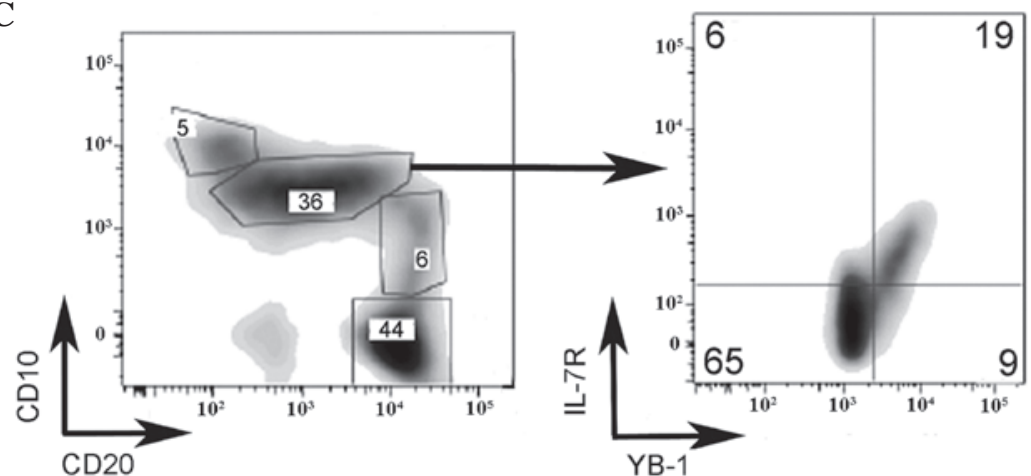

Figure 1. YB-1 is significantly higher in BCP ALL, at diagnosis and relapse, compared with normal counterparts. Flow cytometric analyses of (A) YB-1 and (B) IL-7R $\alpha$ expression in BCP cells from the bone marrow of healthy individuals and pediatric BCP ALL patients at diagnosis and at relapse. Normal BCP cells were defined by a $\mathrm{CD} 45^{\mathrm{dim}} / \mathrm{CD} 19^{+} / \mathrm{CD} 10^{+}$phenotype. The number of samples evaluated in each case is indicated on each plot. Results are presented as a box and whisker plot (Tukey method). (C) Evaluation of normal BCP subsets (percentage of total BCP population is indicated in each box) revealed an IL-7R $\alpha /$ YB-1-expressing subpopulation within the $\mathrm{CD} 10^{+} / \mathrm{CD} 20^{\mathrm{dim}}$ subset. ${ }^{*} \mathrm{P}<0.05,{ }^{* * *} \mathrm{P}<0.005,{ }^{* * * * *} \mathrm{P}<0.0001$. YB-1, Y-box-binding protein-1; IL-7R $\alpha$, interleukin-7 receptor $\alpha$; BCP, B-cell precursor; ALL, acute lymphoblastic leukemia; diag., diagnosis; rel., relapse; CD, cluster of differentiation; MFI, mean fluorescence intensity.

determined $18 \mathrm{~h}$ later (Fig. 5C). In the presence of IL-7, MEK inhibition increased the rate of rapamycin-induced apoptosis from 9-33\% ( $\mathrm{P}<0.001)$. Additionally, MEK inhibition increased rapamycin-mediated apoptosis in cells not treated with IL-7 (from 24-41\%, P<0.001) indicating downstream involvement of additional, IL-7-independent survival pathways. However, the U0126-mediated increase in cell death was greater in IL-7-treated cells than untreated cells (3.8 fold vs. 1.8 fold, $\mathrm{P}<0.001)$, indicating a significant contribution from IL-7-mediated survival pathways. These results identify YB-1 as a significant factor in the IL-7-mediated protection of $\mathrm{BCP}$ ALL against rapamycin.

\section{Discussion}

To the best of our knowledge, the present study provides the first evidence for the involvement of YB-1 in IL-7 signaling in $\mathrm{B}$ cells. The results suggest that crosstalk occurs between these proteins, with increased YB-1 levels contributing to IL-7R $\alpha$ upregulation, and IL-7 signaling leading to YB-1 phosphorylation. While the full implications of this interaction remain unknown, the crosstalk mediates a clear survival signal for BCP ALL cells. Although the current study is limited by the lack of matched samples, the increase in YB-1 expression between diagnosis and relapse ALL samples is in accordance with its role in chemotherapy resistance described for other malignancies $(24,25)$ and suggests the physiological relevance of this pathway for survival during therapy. Although YB-1 has not been identified in RNA microarray-based studies comparing BCP ALL samples at diagnosis and relapse, evidence is emerging that indicates that this protein is largely regulated at a post-transcriptional level (41).

The IL-7 receptor and YB-1 are overexpressed in malignant compared with normal BCP cells. It has been demonstrated that YB-1 increases the expression of growth factor receptors in prostate and breast cancer $(19,20)$. Transfection of YB-1 into normal B cells led to the upregulation of YB-1 expression in the majority of transfected cells; however, the induction of IL-7R $\alpha$ expression occurred in only a proportion of these, suggesting that this relationship is influenced by additional factors. These data support the hypothesis that YB-1 may contribute to IL-7R $\alpha$ overexpression, which in turn may contribute to the development or maintenance of malignant BCP cells by binding IL-7 or thymic stromal lymphopoietin (TSLP) (42), a cytokine which signals through a dimer composed of cytokine receptor-like factor 2 and IL-7R $\alpha$. The pro-leukemic potential of such signaling is suggested by the gain of function mutations in IL-7R $\alpha$ or associated pathways that occur in the context of TSLP signaling and have been described in BCP ALL $(43,44)$. 
A GFP

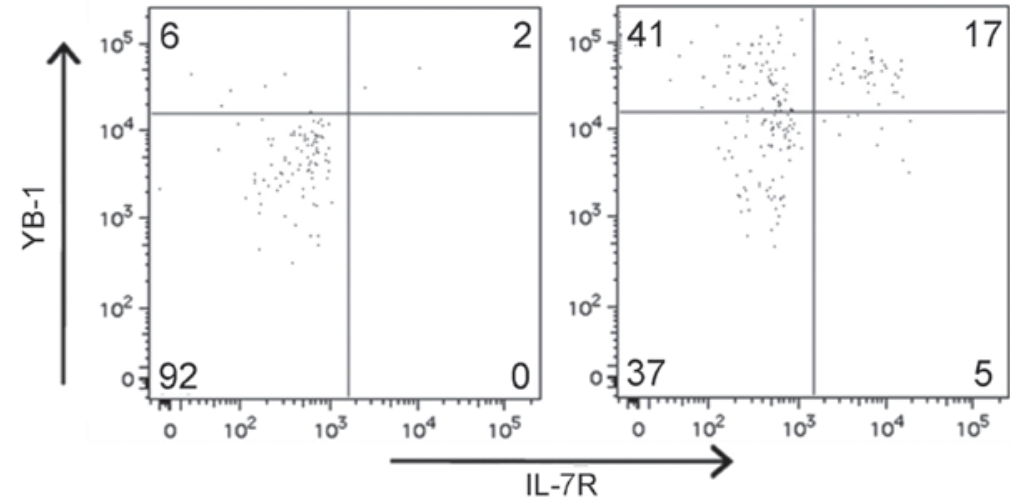

B

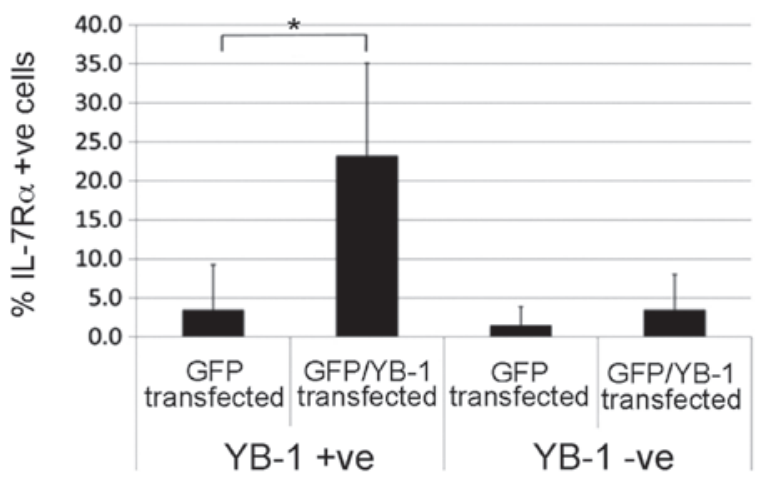

Figure 2. Overexpression of YB-1 increases surface IL-7R $\alpha$ levels. (A) Representative dot plots showing CD19+/GFP ${ }^{\text {hi }}$ cells stained with anti-YB-1 and anti-IL-7R following transfection with a GFP control plasmid (left panel) or YB-1/GFP plasmid (right panel). The percentage of the total cells is indicated in each quadrant. (B) Cumulative results of 4 overexpression experiments ( $n=2$ for cord blood and $n=2$ for peripheral blood) showing the percentage of GFP ${ }^{+}$ cells expressing IL-7R $\alpha$ (plotted as the mean + standard error of the mean). "P<0.05. IL-7R $\alpha$, interleukin-7 receptor $\alpha$; CD, cluster of differentiation; YB-1, Y-box-binding protein-1; GFP, green fluorescent protein.

A

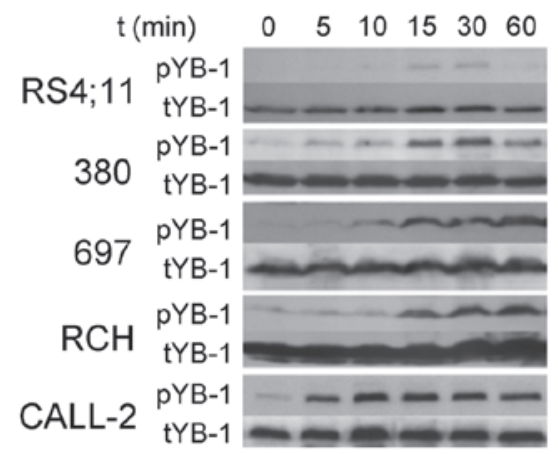

B
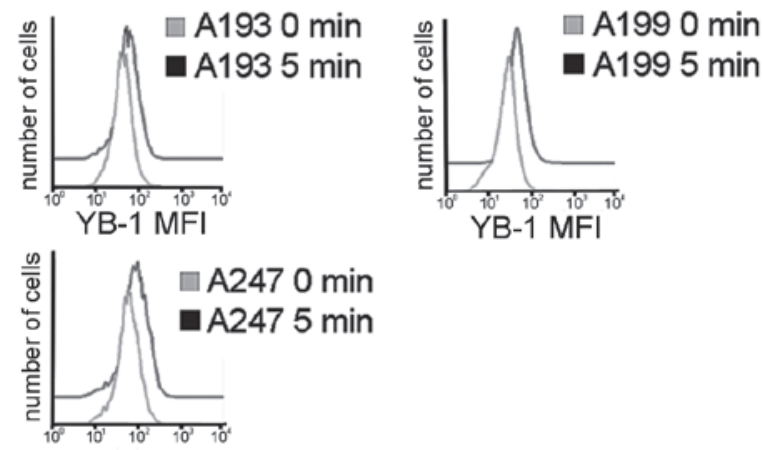

YB-1 MFI

Figure 3. IL-7 induces YB-1 phosphorylation in BCP ALL cell lines and in primary patient samples. (A) Western blot analysis of BCP ALL cell lines (RS4;11, $380,697, \mathrm{RCH}$ and CALL-2) for pYB-1. Cell lines were serum-starved for $24 \mathrm{~h}$, stimulated with $25 \mathrm{ng} / \mathrm{ml} \mathrm{IL-7} \mathrm{for} \mathrm{0-60} \mathrm{min} \mathrm{and} \mathrm{sequentially} \mathrm{probed} \mathrm{with}$ anti-pYB-1 (S102) and anti-tYB-1 antibodies. (B) Flow cytometric determination of pYB-1 following IL-7 stimulation of BCP ALL samples. Primary samples, expanded in NOD.Cg-Prkdc $c^{s c i d} / I L 2 \mathrm{rg}^{t \mathrm{~m} I \mathrm{Wl} l} / \mathrm{SzJ}$ mice, were thawed, rested for $1.5 \mathrm{~h}$ in serum-free medium and stimulated with $25 \mathrm{ng} / \mathrm{ml} \mathrm{IL}-7$ for the indicated times. Histograms of pYB-1 from each expanded patient sample prior to and following stimulation with IL-7 at the time of maximum phosphorylation are presented. IL-7, interleukin-7; YB-1, Y-box-binding protein-1; pYB-1, phosphorylated YB-1; tYB-1, total YB-1; BCP, B-cell precursor; ALL, acute lymphoblastic leukemia.

Addition of IL-7 to BCP ALL cells induces YB-1 phosphorylation at $\mathrm{S} 102$. In previous studies using breast cancer cells, Akt $(16,18)$ and RSK (34) have been implicated as the serine kinase responsible for YB-1 phosphorylation; the signaling pathway may vary according to cell type and environmental context. In the current study, the pharmacological blockade of ERK1/2 signaling by MEK1/2 inhibition, but not of Akt signaling by PI3K inhibition, completely abolished the IL-7-mediated phosphorylation of S102. Downstream targets of ERK remain to be identified; however, RSK2, which phosphorylates YB-1 in breast cancer cells (34) and is induced by IL-7 in BCP ALL, is a primary candidate. Phosphorylation of 
A

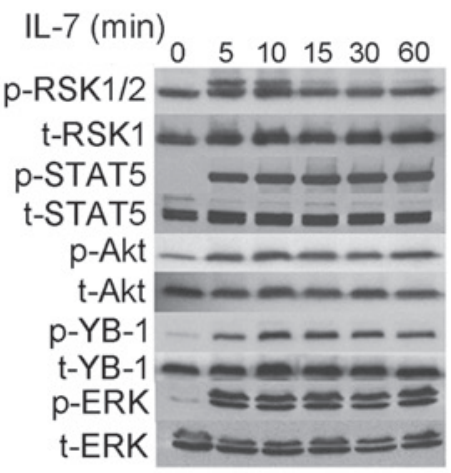

B

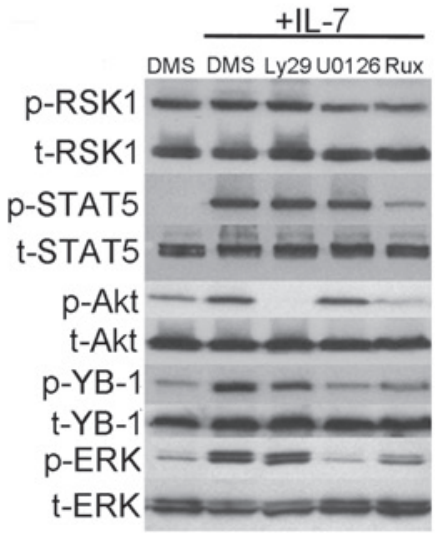

C

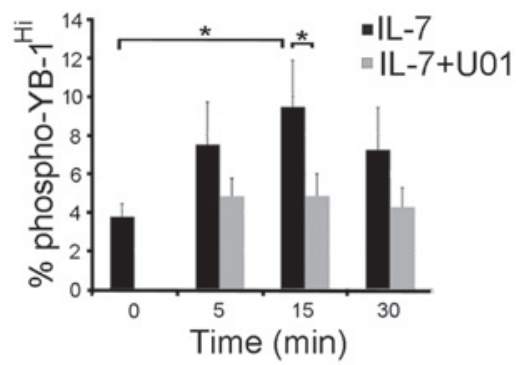

Figure 4. IL-7-mediated phosphorylation of YB-1 is MEK1-dependent but PI3K/AKT independent. Cells were serum-starved for $24 \mathrm{~h}$ prior to IL-7 stimulation. Lysates were then probed with antibodies specific for phosphorylated (phosphoRSK S221, phosphoSTAT5 Y694, phosphoAkt S473, phosphoYB-1 S102, phosphoERK1/2 T202/Y204) and total proteins. (A) A time course of phosphorylation responses to IL-7 added for the indicated durations. (B) Inhibition

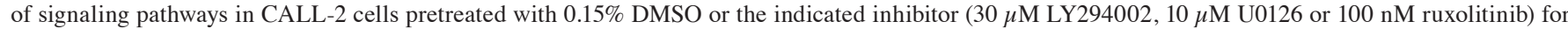
$2 \mathrm{~h}$ prior to the addition of IL-7 for $30 \mathrm{~min}$. Blots are representative of at $\geq 3$ different experiments. (C) Inhibition of YB-1 phosphorylation with U0126 in expanded patient samples. An arbitrary gate was used to define phospho-YB-1 $1^{\text {hi }}$ and applied to all samples; the percentage of phospho-YB-1 ${ }^{\text {hi }}$ cells prior to and following stimulation with $25 \mathrm{ng} / \mathrm{ml} \mathrm{IL-7} \mathrm{with} \mathrm{and} \mathrm{without} \mathrm{prior} \mathrm{treatment} \mathrm{with} 10 \mu \mathrm{M}$ U0126 are presented. The graph shows the averages from three NSG-expanded cell lines (A193, A247 and A199), each repeated three times. ${ }^{*} \mathrm{P}<0.05$. NSG mice, NOD.Cg-Prkdc $c^{\text {scid } / I L 2 r^{t m l}{ }^{t m j l} / S z J}$ mice; IL-7, interleukin 7; YB-1, Y-box-binding protein-1; p-YB-1, phosphorylated Y-box-binding protein 1; STAT5, signal transducer and activator of transcription 5; DMSO/DMS, dimethyl sulfoxide; U0126, MEK1/2 inhibitor; Ly29, LY294002.

A
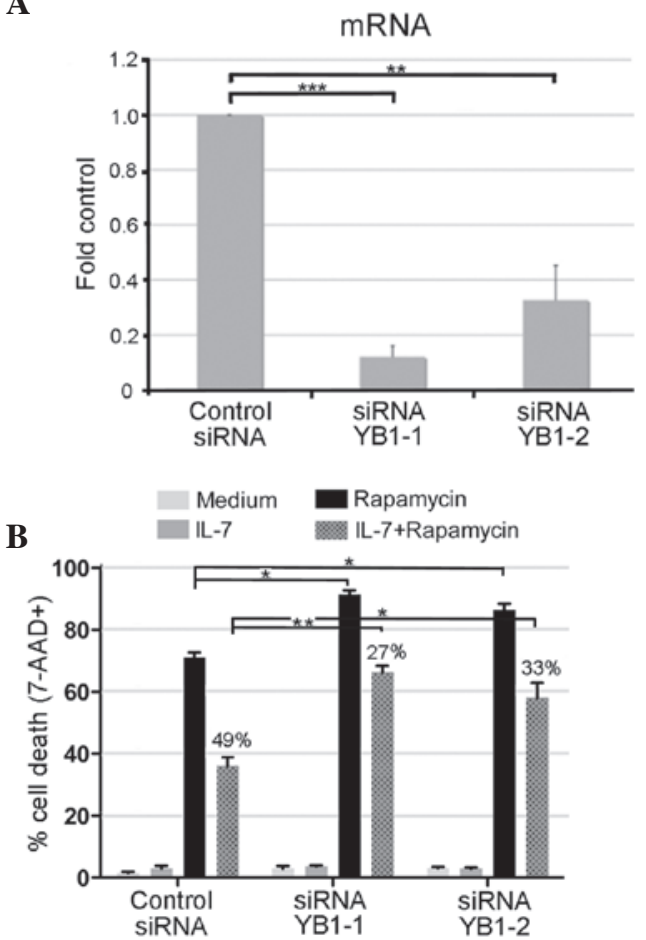

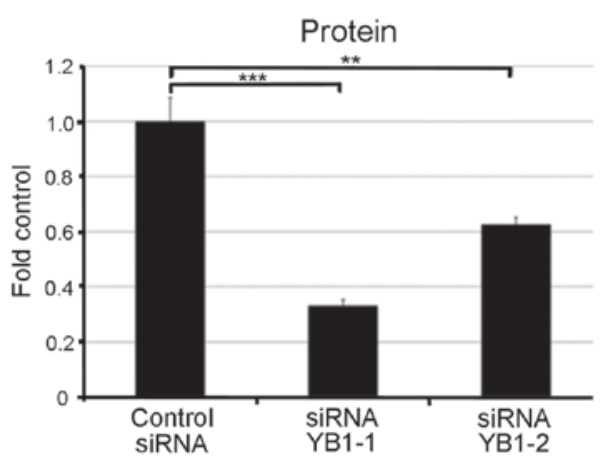

C

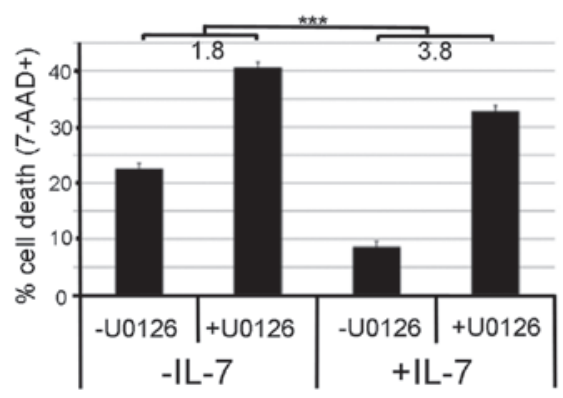

Figure 5. YB-1 contributes to IL-7-mediated protection against rapamycin-induced cell death. CALL-2 cells were electroporated with $200 \mathrm{nM}$ non-specific control siRNA, siRNA YB-1-1 or siRNA YB-1-2. Figures are compiled from a minimum of three experiments. (A) YB-1 siRNA-mediated knockdown of mRNA (left panel) and protein (right panel) $72 \mathrm{~h}$ after transfection. Results are expressed as the fold of the negative control + standard deviation. (B) YB-1 involvement in IL-7 protection against rapamycin challenge. CALL-2 cells were transfected with siRNA against YB-1 or control siRNA, and $48 \mathrm{~h}$ later they were treated overnight with medium or $25 \mathrm{ng} / \mathrm{ml} \mathrm{IL}-7$, and then for further $8 \mathrm{~h}$ with or without $140 \mu \mathrm{M}$ rapamycin. The average percentage of dead cells + standard error of the mean compiled from three experiments are presented and the numbers indicate the percentage of rescue following IL-7 treatment compared with cells transfected with control siRNA. (C) The effect of a combination of U0126 and rapamycin in the absence and presence of IL-7. CALL-2 cells were treated with $10 \mu \mathrm{M}$ U0126 or vehicle for $2 \mathrm{~h}$ prior to overnight stimulation with PBS or $25 \mathrm{ng} / \mathrm{ml}$ IL-7. U0126 and PBS or IL-7 treatment was repeated the next day. Cells were incubated for a further $18 \mathrm{~h}$ with $34 \mu \mathrm{M}$ rapamycin $30 \mathrm{~min}$ after the second addition of IL-7 and the percentage of cell death was determined by 7-AAD exclusion. Results from three independent experiments are presented. Numbers indicate the fold difference with and without IL-7 treatment. ${ }^{*} \mathrm{P}<0.01,{ }^{* * *} \mathrm{P}<0.005,{ }^{* * *} \mathrm{P}<0.001$. siRNA, small interfering RNA; IL-7, interleukin 7; YB-1, Y-box-binding protein-1; PBS, phosphate-buffered saline; STAT5, signal transducer and activator of transcription 5; DMSO, dimethyl sulfoxide; U0126, MEK1/2 inhibitor; 7-AAD, 7-aminoactinomycin D. 
YB-1 ${ }^{\text {S102 }}$ activates the translation of mRNA involved in growth and survival, while direct phosphorylation or subsequent stress induces nuclear localization enabling YB-1 to exert transcriptional control on a further subset of genes, including those involved in drug resistance $(16,45)$. In contrast to results from studies on squamous carcinoma cells (46), reduced leukemia cell viability was not observed following YB-1 knockdown alone. The current study, however, implicates the activation of YB-1 by IL-7 as a mechanism contributing to the survival of BCP ALL in the presence of cytotoxic stressors.

IL-7 inhibits the induction of apoptosis by the mTOR inhibitor rapamycin (13). Curtailment of YB-1 activity, through targeted knockdown or pharmacological inhibition, reduced the IL-7-mediated protection against rapamycin. mTOR is a translational regulator of mRNA which is involved in cell cycle progression, proliferation and survival. IL-7, mTOR and YB-1 may work in synergy to augment survival: IL-7 can induce mTOR downstream of Akt (47), YB-1 is involved in the mTOR-mediated increase of translation downstream of growth factor-induced PI3K/Akt (15), and mTOR may influence the translation of YB-1 (41). IL-7-mediated induction of YB-1 requires ERK rather than Akt in BCP ALL, and the induced survival pathway is effective against inhibitors of mTOR; therefore, it is assumed that this pathway is at least partly mTOR-independent. Factors downstream of IL-7 and YB-1 that contribute to increased survival remain to be determined. One potential explanation is increased expression of the ATP-binding cassette transporter multi-drug resistance 1 , which is known to influence YB-1-mediated drug resistance $(25,27)$. When activated downstream of IL-7, YB-1 may also contribute to survival by stimulating a STAT5-mediated increase in B-cell lymphoma 2 expression $(38,48)$. Finally, it must be noted that the ability of IL-7 to protect cells from cytotoxins may be difficult to observe in cell monocultures as it is likely to depend on interaction with stromal cells (49).

In conclusion, although the functional analysis of the present study is limited to BCP ALL cells, the observation that YB-1 and IL-7R $\alpha$ expression are closely correlated in a non-malignant subset of BCP cells, and that augmented YB-1 expression drives increased IL-7R levels on normal CD19 ${ }^{+} \mathrm{B}$ cells, suggests that this novel interaction may also have relevance to B cell biology. The similarly elevated levels of YB-1 in BCP ALL cells at diagnosis and in the normal BCP cell subset is intriguing; however, further studies are required to determine whether this reflects the fact that leukemia frequently arises from this subset of BCP cells or that there is selective pressure for ALL cells to recapitulate the pathway. YB-1 directs differentiation, proliferation and survival programs in a broad range of cells (25); therefore, it is conceivable that YB-1 pathways mediate the expression of factors that facilitate transformation by increasing the potential for self-renewal and drug resistance, as has been reported for breast cancer cells (50). Overall, the results of the present study suggest that inhibition of YB-1 may represent a novel strategy to increase the susceptibility of BCP ALL to mTOR inhibitors.

\section{Acknowledgements}

The authors would like to thank the following CFRI-affiliated researchers: Mr. Johan VanMeerlo for providing technical support, Dr Laura Sly and Dr Chinten James Lim for useful discussions, Dr Pascal Lavoie for arranging cord blood, and from Life Technologies, Dr. John Verberg for providing technical support. The current study was supported by the Michael Cuccione Foundation at British Columbia Children's Hospital and by a grant from the Canadian Institute for Health Research (no. MOP-97905).

\section{References}

1. Pui CH, Relling MV and Downing JR: Acute lymphoblastic leukemia. N Engl J Med 350: 1535-1548, 2004.

2. Tsai AG, Lu H, Raghavan SC, Muschen M, Hsieh CL and Lieber MR: Human chromosomal translocations at $\mathrm{CpG}$ sites and a theoretical basis for their lineage and stage specificity. Cell 135: 1130-1142, 2008.

3. Papaemmanuil E, Rapado I, Li Y, Potter NE, Wedge DC, Tubio J, Alexandrov LB, Van Loo P, Cooke SL, Marshall J, et al: RAG-mediated recombination is the predominant driver of oncogenic rearrangement in ETV6-RUNX1 acute lymphoblastic leukemia. Nat Genet 46: 116-125, 2014.

4. Swaminathan S, Klemm L, Park E, Papaemmanuil E, Ford A, Kweon SM, Trageser D, Hasselfeld B, Henke N, Mooster J, et al: Mechanisms of clonal evolution in childhood acute lymphoblastic leukemia. Nat Immunol 16: 766-774, 2015.

5. Mandal M, Powers SE, Ochiai K, Georgopoulos K, Kee BL, Singh $\mathrm{H}$ and Clark MR: Ras orchestrates exit from the cell cycle and light-chain recombination during early B cell development. Nat Immunol 10: 1110-1117, 2009.

6. Corcoran AE, Smart FM, Cowling RJ, Crompton T, Owen MJ and Venkitaraman AR: The interleukin-7 receptor alpha chain transmits distinct signals for proliferation and differentiation during B lymphopoiesis. EMBO J 15: 1924-1932, 1996.

7. Milne CD and Paige CJ: IL-7: A key regulator of B lymphopoiesis. Semin Immunol 18: 20-30, 2006.

8. Touw I, Pouwels K, van Agthoven T, van Gurp R, Budel L, Hoogerbrugge H, Delwel R, Goodwin R, Namen A and Löwenberg B: Interleukin-7 is a growth factor of precursor B and T acute lymphoblastic leukemia. Blood 75: 2097-2101, 1990.

9. Nishii K, Katayama N, Miwa H, Shikami M, Masuya M, Shiku H and Kita K: Survival of human leukaemic B-cell precursors is supported by stromal cells and cytokines: Association with the expression of bcl-2 protein. Br J Haematol 105: 701-710, 1999.

10. Barata JT, Keenan TD, Silva A, Nadler LM, Boussiotis VA and Cardoso AA: Common gamma chain-signaling cytokines promote proliferation of T-cell lymphoblastic leukemia. Haematologica 89: 1459-1467, 2004.

11. Silva A, Laranjeira AB, Martins LR, Cardoso BA, Demengeot J, Yunes JA, Seddon B and Barata JT: IL-7 contributes to the progression of human T-cell acute lymphoblastic leukemias. Cancer Res 71: 4780-4789, 2011.

12. Thiant S, Yakoub-Agha I, Magro L, Trauet J, Coiteux V, Jouet JP, Dessaint JP and Labalette M: Plasma levels of IL-7 and IL-15 in the first month after myeloablative BMT are predictive biomarkers of both acute GVHD and relapse. Bone Marrow Transplant 45: 1546-1552, 2010

13. Brown VI, Fang J, Alcorn K, Barr R, Kim JM, Wasserman R and Grupp SA: Rapamycin is active against B-precursor leukemia in vitro and in vivo, an effect that is modulated by IL-7-mediated signaling. Proc Natl Acad Sci USA 100: 15113-15118, 2003.

14. Kosnopfel C, Sinnberg T and Schittek B: Y-box binding protein 1-A prognostic marker and target in tumour therapy. Eur J Cell Biol 93: 61-70, 2014.

15. Evdokimova V, Ovchinnikov LP and Sorensen PH: Y-box binding protein 1: Providing a new angle on translational regulation. Cell Cycle 5: 1143-1147, 2006.

16. Evdokimova V, Ruzanov P, Anglesio MS, Sorokin AV, Ovchinnikov LP, Buckley J, Triche TJ, Sonenberg N and Sorensen PH: Akt-mediated YB-1 phosphorylation activates translation of silent mRNA species. Mol Cell Biol 26: 277-292, 2006.

17. Koike K, Uchiumi T, Ohga T, Toh S, Wada M, Kohno K and Kuwano M: Nuclear translocation of the Y-box binding protein by ultraviolet irradiation. FEBS Lett 417: 390-394, 1997.

18. Sutherland BW, Kucab J, Wu J, Lee C, Cheang MC, Yorida E, Turbin D, Dedhar S, Nelson C, Pollak M, et al: Akt phosphorylates the Y-box binding protein 1 at Ser102 located in the cold shock domain and affects the anchorage-independent growth of breast cancer cells. Oncogene 24: 4281-4292, 2005. 
19. Shiota M, Takeuchi A, Song Y, Yokomizo A, Kashiwagi E, Uchiumi T, Kuroiwa K, Tatsugami K, Fujimoto N, Oda Y and Naito S: Y-box binding protein-1 promotes castration-resistant prostate cancer growth via androgen receptor expression. Endocr Relat Cancer 18: 505-517, 2011.

20. Stratford AL, Habibi G, Astanehe A, Jiang H, Hu K, Park E, Shadeo A, Buys TP, Lam W, Pugh T, et al: Epidermal growth factor receptor (EGFR) is transcriptionally induced by the Y-box binding protein-1 (YB-1) and can be inhibited with Iressa in basal-like breast cancer, providing a potential target for therapy. Breast Cancer Res 9: R61, 2007.

21. Davies AH and Dunn SE: YB-1 drives preneoplastic progression: Insight into opportunities for cancer prevention. Oncotarget 2 : 401-406, 2011

22. Kim ER, Selyutina AA, Buldakov IA, Evdokimova V, Ovchinnikov LP and Sorokin AV: The proteolytic YB-1 fragment interacts with DNA repair machinery and enhances survival during DNA damaging stress. Cell Cycle 12: 3791-3803, 2013.

23. Bargou RC, Jürchott K, Wagener C, Bergmann S, Metzner S, Bommert K, Mapara MY, Winzer KJ, Dietel M, Dörken B and Royer HD: Nuclear localization and increased levels of transcription factor YB-1 in primary human breast cancers are associated with intrinsic MDR1 gene expression. Nat Med 3: 447-450, 1997.

24. Chatterjee M, Rancso C, Stühmer T, Eckstein N, Andrulis M, Gerecke C, Lorentz H, Royer HD and Bargou RC: The Y-box binding protein $\mathrm{YB}-1$ is associated with progressive disease and mediates survival and drug resistance in multiple myeloma. Blood 111: 3714-3722, 2008

25. Lasham A, Print CG, Woolley AG, Dunn SE and Braithwaite AW: YB-1: Oncoprotein, prognostic marker and therapeutic target? Biochem J 449: 11-23, 2013.

26. Szczuraszek K, Halon A, Materna V, Mazur G, Wrobel T, Kuliczkowski K, Donizy P, Holm PS, Lage H and Surowiak P: Elevated YB-1 expression is a new unfavorable prognostic factor in non-Hodgkin's lymphomas. Anticancer Res 31: 2963-2970, 2011.

27. Shen H, Xu W, Luo W, Zhou L, Yong W, Chen F, Wu C, Chen Q and Han X: Upregulation of mdrl gene is related to activation of the MAPK/ERK signal transduction pathway and YB-1 nuclear translocation in B-cell lymphoma. Exp Hematol 39: 558-569, 2011.

28. Hanzawa K, Momose S, Higashi M, Tokuhira M, Watanabe R, Kajino K, Hino O, Itoyama S, Kizaki M and Tamaru J: Y-box binding protein-1 expression in diffuse large B-cell lymphoma An impact on prognosis in the rituximab era. Leuk Lymphoma 51: 2054-2062, 2010.

29. Castellana B, Aasen T, Moreno-Bueno G, Dunn SE and Ramón y Cajal S: Interplay between YB-1 and IL-6 promotes the metastatic phenotype in breast cancer cells. Oncotarget 6 : 38239-38256, 2015.

30. Barrett DM, Seif AE, Carpenito C, Teachey DT, Fish JD, June CH, Grupp SA and Reid GS: Noninvasive bioluminescent imaging of primary patient acute lymphoblastic leukemia: A strategy for preclinical modeling. Blood 118: e112-e117, 2011

31. Livak KJ and Schmittgen TD: Analysis of relative gene expression data using real-time quantitative PCR and the 2(-Delta Delta C(T)) Method. Methods 25: 402-408, 2001

32. Guay D, Evoy AA, Paquet E, Garand C, Bachvarova M, Bachvarov D and Lebel $\mathrm{M}$ : The strand separation and nuclease activities associated with YB-1 are dispensable for cisplatin resistance but overexpression of YB-1 in MCF7 and MDA-MB-231 breast tumor cells generates several chemoresistance signatures. Int J Biochem Cell Biol 40: 2492-2507, 2008

33. Brown VI, Fang J, Alcorn K, Barr R, Kim JM, Wasserman R and Grupp SA: Rapamycin is active against B-precursor leukemia in vitro and in vivo, an effect that is modulated by IL-7-mediated signaling. Proc Natl Acad Sci USA 100: 15113-15118, 2003.

34. Fujii T, Kawahara A, Basaki Y, Hattori S, Nakashima K, Nakano K, Shirouzu K, Kohno K, Yanagawa T, Yamana H, et al: Expression of HER2 and estrogen receptor alpha depends upon nuclear localization of Y-box binding protein-1 in human breast cancers. Cancer Res 68: 1504-1512, 2008.
35. Basaki Y, Hosoi F, Oda Y, Fotovati A, Maruyama Y, Oie S, Ono M, Izumi $\mathrm{H}$, Kohno K, Sakai K, et al: Akt-dependent nuclear localization of Y-box-binding protein 1 in acquisition of malignant characteristics by human ovarian cancer cells. Oncogene 26: 2736-2746, 2007.

36. Stratford AL, Fry CJ, Desilets C, Davies AH, Cho YY, Li Y, Dong Z, Berquin IM, Roux PP and Dunn SE: Y-box binding protein-1 serine 102 is a downstream target of $\mathrm{p} 90$ ribosomal S6 kinase in basal-like breast cancer cells. Breast Cancer Res 10: R99, 2008.

37. van der Plas DC, Smiers F, Pouwels K, Hoefsloot LH, Löwenberg B and Touw IP: Interleukin-7 signaling in human B cell precursor acute lymphoblastic leukemia cells and murine BAF3 cells involves activation of STAT1 and STAT5 mediated via the interleukin-7 receptor alpha chain. Leukemia 10: $1317-1325,1996$

38. Venkitaraman AR and Cowling RJ: Interleukin-7 induces the association of phosphatidylinositol 3-kinase with the alpha chain of the interleukin-7 receptor. Eur J Immunol 24: 2168-2174, 1994.

39. Steelman LS, Abrams SL, Whelan J, Bertrand FE, Ludwig DE, Bäsecke J, Libra M, Stivala F, Milella M, Tafuri A, et al: Contributions of the Raf/MEK/ERK, PI3K/PTEN/Akt/mTOR and Jak/STAT pathways to leukemia. Leukemia 22: 686-707, 2008.

40. Fleming HE and Paige CJ: Pre-B cell receptor signaling mediates selective response to IL-7 at the Pro-B to Pre-B cell transition via an ERK/MAP kinase-dependent pathway. Immunity 15: 521-531, 2001.

41. Lyabin DN, Eliseeva IA and Ovchinnikov LP: YB-1 synthesis is regulated by mTOR signaling pathway. PLoS One 7: e52527, 2012.

42. Brown VI, Hulitt J, Fish J, Sheen C, Bruno M, Xu Q, Carroll M, Fang J, Teachey D and Grupp SA: Thymic stromal-derived lymphopoietin induces proliferation of pre-B leukemia and antagonizes mTOR inhibitors, suggesting a role for interleukin-7Ralpha signaling. Cancer Res 67: 9963-9970, 2007.

43. Shochat C, Tal N, Bandapalli OR, Palmi C, Ganmore I, te Kronnie G, Cario G, Cazzaniga G, Kulozik AE, Stanulla M, et al: Gain-of-function mutations in interleukin-7 receptor- $\alpha$ (IL7R) in childhood acute lymphoblastic leukemias. J Exp Med 208: 901-908, 2011.

44. Zenatti PP, Ribeiro D, Li W, Zuurbier L, Silva MC, Paganin M, Tritapoe J, Hixon JA, Silveira AB, Cardoso BA, et al: Oncogenic IL7R gain-of-function mutations in childhood T-cell acute lymphoblastic leukemia. Nat Genet 43: 932-939, 2011.

45. Somasekharan SP, Stoynov N, Rotblat B, Leprivier G, Galpin JD, Ahern CA, Foster LJ and Sorensen PH: Identification and quantification of newly synthesized proteins translationally regulated by YB-1 using a novel Click-SILAC approach. J Proteomics 77: e1-e10, 2012.

46. Troiano A, Lomoriello IS, di Martino O, Fusco S, Pollice A, Vivo M, La Mantia G and Calabrò V: Y-box binding Protein-1 Is part of a complex molecular network linking $\Delta \mathrm{Np} 63 \alpha$ to the PI3K/akt pathway in cutaneous squamous cell carcinoma. J Cell Physiol 230: 2067-2074, 2015.

47. Silva A, Cebola I, Santos CI, Antunes F and Barata JT: Intracellular reactive oxygen species are essential for PI3K/Akt/mTOR-dependent IL-7-mediated viability of T-cell acute lymphoblastic leukemia cells. Leukemia 25: 960-967, 2011.

48. Winston LA and Hunter T: JAK2, Ras, and Raf are required for activation of extracellular signal-regulated kinase/mitogen-activated protein kinase by growth hormone. J Biol Chem 270: 30837-30840, 1995.

49. Johnson SE, Shah N, Panoskaltsis-Mortari A and LeBien TW: Murine and human IL-7 activate STAT5 and induce proliferation of normal human pro-B cells. J Immunol 175: 7325-7331, 2005

50. To K, Fotovati A, Reipas KM, Law JH, Hu K, Wang J, Astanehe A, Davies AH, Lee L, Stratford AL, et al: Y-box binding protein-1 induces the expression of CD44 and CD49f leading to enhanced self-renewal, mammosphere growth, and drug resistance. Cancer Res 70: 2840-2851, 2010. 